or please our fancy, and to destroy those with unfavorable qualities, is the function of artificial selection. Add to this the occasional crossing of unlike forms to promote new and desirable variations, and we have the whole secret of selective breeding. This process Youatt calls the "magician's wand" by which man may summon up and bring into existence any form of animal or plant useful to him or pleasing to his fancy.

Among the greatest triumphs of the applied sciences of our times is the creation of new plants, of new fruits, and new flowers, by the use of known laws of heredity and variation by the skillful hand of Luther Burbank. There is nothing magical or mysterious in all this. "Like the seed is the harvest." The art lies in choosing the right seed.

By the law of probabilities as developed by Quetelet, there will appear in each generation the same number of potential poets, artists, investigators, patriots, athletes and superior men of each degree.

But this law involves the theory of continuity of paternity, that in each generation a percentage practically equal of men of superior mentality should survive to take the responsibilities of parenthood. Otherwise Quetelet's law becomes subject to the operation of another law, the operation of reversed selection, or the biological "law of diminishing returns." In other words, breeding from an inferior stock is the sole agency in race degeneration, as selection natural or artificial along one line or another is the sole agency in race progress.

And all laws of probabilities and of averages are subject to a still higher law, the primal law of biology, which no cross-current of life can overrule or modify: Like the seed is the harvest.

\title{
MAN AND THE LAWS OF HEREDITY.
}

By Vernon lymon Kellogg, Leland Stanford, Calif.

The "laws" of nature, expressed in human language, have nothing of necessity in them. They are expressions of human experience of the order of nature. They are at once the concise description of past events and the confident prophecy of future ones. The law of gravitation is not an expression of the cause of the apple's falling, but a description of the phenomenon, and an expression of our confidence in its eternal repetition. Of the same character are the laws of heredity, of which we hear so much in the meetings of our Association. These laws describe as succinctly as possible the discoveries of our observation and experiment in relation to the reappearance in progeny of ancestral traits. At 
the same time, they express our confidence in a certain order or regularity in this reappearance or repetition of characteristics. A considerable part of our science of eugenics is based upon the knowledge of the order of inheritance which we assume in our formulation of these laws of heredity. Is this foundation a firm one?

An affirmative answer to this question will depend upon the confidence with which we can accept the formulated results of much observation and some experimentation on inheritance behavior in the lower animals and also upon the confidence with which we can accept the identity of this order of inheritance in the lower animals with that in man. For however keenly these studies and descriptions of heredity in various lower animals may interest us as students of nature, it is.only the order of heredity in man that is actually of importance to us as students of human eugenics.

The statement can fairly be made that we may now claim with great confidence a considerable and sound beginning in a knowledge of the order of inheritance in plants and the lower animals; a knowledge based not alone on miscellaneous and fortuitous observation, but on planned specific experimentation. Ever since the days of Francis Galton's pioneering studies in heredity, observation, and, latterly, experiment, have steadily and increasingly yielded scientific knowledge of inheritance phenomena until in these present post-Mendelian years, no phase of biological research is being more fruitfully prosecuted.

These results are being slowly and carefully formulated as "laws of heredity;" that is, as terse generalizings of the product of extensive, various and repeated observation and experiment. And the layman may confidently rely upon these generalizations as having the weight of the consensus of scientific authority, as being the well-guarded expression of a hardly-won and keenly-tested body of scientific knowledge.

In no other field of human striving for knowledge is the tendency to premature generalization, to unwarranted dogmatism, to insufficiently grounded law-making, more speedily rebuked or more severely checked by the knowledge-seekers themselves than in the field of science. Let a swiftly-generalizing Hæckel or a speculative Weismann lift his head too soon or too high, and lo! it becomes at once the target for the shafts of his whole world of scientific confrères.

So we may rely with confidence sufficient for going ahead with our foundation-building on the stones offered us for this foundation by the law-making students of heredity. Only before we can make the particular use of these stones that we desire to make we must be assured of 
another fact. We must be confident of the safe carrying over and application to the human species of these laws derived from the study of the lower organisms.

This is no new dilemma in the history of the biological study of man. For how many centuries did that knowledge of the anatomy and physiology of the human species upon which the practice of medicine depends have to be derived by relying on the homologies between the human body and that of the lower animals? Dissection of the human body was for a long, long time a forbidden practice. The philanthropic end was held not to justify the means. The desecration of the sacred human cadaver was a sacrilege and irreverence too great to be pardoned. And hence if man had not happened to be made somewhat in the image of his devoted household companions, the dog and cat, as well as in the image of his intangible and unknowable Creator, his structural and physiological make-up would have remained for much longer than it did a sacred mystery to him.

Today man yields his body to observation. But he is still practically immune from experiment, and probably always will be. Even those devoted whipping boys of his, the dog and the cat, are comparatively free from experimental molestation for the sake of science. There is a louder cry today in England for the protection of the dog from the brutalities of the vivisectionist and experimentalist than for the protection and restoration of man from the injuries of accident and disease.

But human anatomy and physiology were in large measure truly and sufficiently revealed on the basis of human homology with the lower animals. This knowledge has since been amended and extended by direct observation of the lifeless human relict itself. It is largely on a similar basis that our present knowledge of the laws of heredity in man has to rest. There is already in hand a very considerable mass of data on the mode of human intelligence gathered by direct observation and the laborious compilation of fortuitous records. Much of Galton's earlier work, invaluable and epoch-making, was of this type. But of direct experiment on human heredity we have no trace, nor probably ever shall have. It is a source of knowledge which by the very nature of our civilization and society is shut off from us. We have then to rely, for our knowledge of inheritance through experiment, on the practical certainty of the homology of man in all his fundamental life attributes with the lower animals.

This then is our situation today. IJaws of heredity are being formulated. These laws are derived chiefly from the study of the lower ani- 
mals. But man is first of all a mammal; he is but one in the scale of organic life. Differing greatly in degree, he is yet almost identical in kind with his animal companions. He is builded on the same plan, out of the same materials. His body and its parts behave as the bodies of the other animals. He submits to the same "laws" of inorganic and organic nature. He falls as the stone falls; he dies without oxygen as the cat does; he reproduces himself exactly as the rabbit and monkey do; he hands on to his progeny the characteristics, expressed or latent, that were handed on to him by his parents, just as do the silkworm, the fowl, the mouse and the guinea-pig. For these lower animals we are formulat- . ing laws of heredity. If our formulations are correct they almost certainly apply to man as well; if they are not correct for him, they are almost certainly as invalid for these lower animals.

\section{SOME DESIDERATA IN THE SCIENCE OF EUGENICS.}

By Frederick Adams Woods, Brookline, Mass.

In submitting a portion of the report on the Committee on Eugenics, I should like to confine myself chiefly to the discussion of certain desiderata in this infantile science. Volumes have already been written on such themes as the relative value of heredity and education, marriage and heredity, insanity and heredity, and other questions equally fundamental in the science of eugenics. A bibliography of human heredity contains upward of five hundred titles without pretending to be complete. Yet of all this number not more than about fifty are, in my opinion, valuable, that is, contain material which subsequent investigators can utilize in constructing a solid and permanent structure which shall endure and grow until it becomes an important and practical monument and a force in national progress.

Just as the post-Darwinian discussions on animal and plant inheritance brought little fruit until the quantitative method was applied, so the future of eugenics lies with the statisticians. We have had essays enough. Nothing shows this more clearly than the contrast between recent studies in heredity made in England and those emanating from the Continent. Following the method of Lombroso, French and German writers have brought out five or six handsome and expensive books in the last three years, dealing with the questions of mental inheritance, insanity and genius. All of these leave the reader where they found him. Citing of instances in favor of a theory is not scientific proof, and the absence of any consistent method in the pursuance of their laborious 